\title{
La obsesión por la memoria frente a la sincronicidad de los soportes mnémicos*
}

Recibido: 22/09/2017 | Revisado: 06/08/2018 | Aceptado: 11/09/2018

DOI: $10.17230 /$ co-herencia.16.30.9

\author{
Rafael Pérez Baquero** \\ rafael.perez4@um.es
}

\begin{abstract}
Resumen El objetivo de este texto es presentar una interpretación sobre las condiciones e implicaciones de la cultura de la memoria que, desde los años ochenta, caracteriza las relaciones que mantienen las sociedades occidentales con su pasado. A partir del ámbito de la filosofía de la historia, pero retomando instrumentos conceptuales de otros campos, interpretamos los límites de este énfasis en el pasado en función de las peculiaridades de los soportes materiales que lo han hecho posible. Dicha tesis rechaza la comprensión de este boom de memoria como una tentativa para establecer una relación premoderna con el pasado o como una mera reacción a la crisis del futuro, evidenciada a finales del siglo Xx. Lo interpretamos, más bien, como un contramovimiento de resistencia a la aplicación de los ritmos de obsolescencia, propios del actual modelo occidental de consumo de información, a nuestro pretérito.
\end{abstract}

\section{Palabras clave:}

Cultura de la memoria, posmemoria, técnica, medios de comunicación, sincronía, sociedad de consumo, filosofía de la historia.

\section{The obsession with memory regarding the synchronicity of mnemonic media}

\begin{abstract}
This paper aims to offer an interpretation of the conditions and implications of the memory culture that has characterized, since the eighties, the relations that Western societies maintain with their past. Drawing on the philosophy of history, but using conceptual tools from other fields, we interpret the limits of this emphasis on the past based on the peculiarities of the material media that have enabled it. This thesis rejects the understanding of this memory boom either as an attempt to establish a premodern relationship with the past or as a mere reaction to the crisis of the future, evidenced in the late the 20th century. Rather, we construe it as a movement to counter the application of an obsolescence pace, which is characteristic of the current western model of information consumption, to our past.
\end{abstract}

\section{Keywords:}

Memory culture, postmemory, technique, mass media, synchrony, consumer society, philosophy of history.
"Este artículo forma parte del proyecto de investigación "Narrar la historia, recordar el trauma. Memoria y olvido de la Guerra Civil Española, ochenta años después", Universidad de Murcia, España. Beca predoctoral, código: Formación del Profesorado Universitario (FPU) 2015/00566. Fecha de inicio: 23 de septiembre de 2016; fecha de terminación: 23 de octubre de 2020.

** Investigador-predoctoral con un contrato en FPU por el Ministerio de Educación, Cultura y Deporte español en la Universidad de Murcia, España. ORCID: 0000-00034942-6427. 
En 1997, la popular página web de bromas, The Onion, publicaba una noticia que, como indica Andreas Huyssen (2007, p. 27), tiene la peculiaridad de captar, mediante el recurso de la hipérbole, algunos de los rasgos de la actual cultura de la memoria. El titular de la noticia anuncia lo siguiente:

El departamento estadounidense de lo Retro avisa: Nos estamos quedando sin pasado. En una conferencia de prensa este lunes, el Secretario de lo Retro Anson Williams comentó la presencia de la amenaza respecto a una "crisis nacional retro", avisando de que "si los actuales niveles de consumo de lo retro en Estados Unidos siguen continuando sin ser vigilados, nos podríamos quedar sin pasado en el año 2005" (Huyssen, 2007, p. 27). ${ }^{1}$

El valor de esta falsa noticia es doble: por un lado, llama la atención acerca de las absurdas consecuencias derivadas de la integración del trato con nuestro pretérito dentro de los ritmos comerciales del consumo, como si nuestro pasado, que por su dimensión ontológica no es, pudiera convertirse en la nueva especie en peligro de extinción, ante la carencia de mesura de nuestro modelo económico y productivo; por otro, nos permite señalar en qué medida la pervivencia del pasado está subordinada a los intereses de los agentes que pueblan ese presente.

Además, esta noticia constituye un síntoma de un proceso histórico vigente, con cada vez más fuerza en nuestras sociedades. Dicho proceso podría ser denominado, como hace Jay Winter, una "explosión de la memoria" (2007); un proceso que se caracteriza por su trasversalidad. Afecta tanto al ámbito de la cultura como al de la política, llegando a infiltrarse en el interior de la vida cotidiana. En relación con el primero, asistimos a una tendente "museización" del pasado más inmediato. Desde los años posteriores a la Segunda Guerra Mundial se acentuaron las prácticas culturales de rememoración colectiva del pasado reciente, un proceso que se potenció tras la caída de la Unión Soviética y la generación de un movimiento cultural que hacía del olvido de las pasadas décadas su anatema. La construcción de museos y memoriales, así como el desarrollo de un mercado (marketing) nostálgico sobre los elementos con mayor valor simbólico de los últimos

1 La noticia original puede encontrarse en The Onion (1997). 
años, dan cuenta de una nueva sensibilidad cultural respecto al pasado. La proliferación de relatos autobiográficos, la ola patrimonial restauradora de monumentos y centros urbanos, la preocupación por los clásicos emblemas de la memoria, la atención pública a los debates históricos en nuevos formatos... pueden ser interpretados como síntomas de esta emergente cultura de la memoria.

Por otro lado, en relación con el ámbito ético-político, tanto el levantamiento de monumentos, como la puesta en práctica de conmemoraciones que mantienen vivos los recuerdos del convulso siglo pasado - especialmente en atención a aquellos que no lo superaron- son otro rasgo de esta explosión de la memoria. La atención a las políticas de justicia transicional, el recurso a la imagen de la víctima como instancia legitimadora, así como el discurso sobre el famoso "deber de memoria" (Mate, 2003), son instancias de la presencia de un "nunca más", de una atención a la imagen del pasado, como eje ético-político común en la fundamentación de las democracias occidentales.

Nuestro objetivo es participar en el análisis de la idiosincrasia, los presupuestos y los límites de este movimiento cultural, interpretado como un síntoma de una forma emergente de temporalidad. Tal pretensión se realiza mediante un estudio sobre las condiciones de este acto colectivo de rememoración que gira en torno a aquello que permite constituirlo como recuerdo: su mantenimiento, estabilidad y vivencia en el presente. Por este motivo, tomamos como hilo conductor el desafío que presenta Huyssen en el siguiente párrafo de En busca del futuro perdido:

Con todos estos fenómenos en marcha, parece plausible preguntar si, una vez que haya pasado el boom de la memoria, existirá realmente alguien que haya recordado algo. Si todo el pasado puede ser vuelto a hacer, ¿acaso no estamos creando nuestras propias ilusiones del pasado mientras nos encontramos atrapados en un presente que cada vez se va achicando más? (2007, p. 18).

Evidentemente, el planteamiento de esta pregunta solo adquiere sentido bajo un horizonte político y cultural que cuestiona la vigencia y la proyección de la actual cultura de la memoria. Al fin y al cabo, la inmersión de estas prácticas rememorativas en el interior de nuestra vida cotidiana se ha realizado a través de los nuevos medios 
de comunicación de masas, especialmente los actuales soportes digitales. Y la crítica según la cual el mercado de la memoria se identifica con el olvido o con la inhibición de facultades cognitivas subjetivas, no es novedosa. Por este motivo, tomamos a los actuales medios de comunicación como pilares o filtros para abordar esta cuestión. Como indica el mismo Huyssen en otra obra: "sugeriría que en este libro los medios de comunicación son el velo oculto a través del cual observo el problema de la memoria cultural y las estructuras de la temporalidad al final del siglo xx" (Huyssen, 1995, p. 18).

El interrogante que formula Huyssen nos lleva a dividir los problemas subyacentes a la actual cultura de la memoria en dos cuestiones diferentes. En primer lugar, al plantear si bajo el horizonte de la cultura mnémica alguien "ha recordado algo", se está problematizando la presencia misma de una retención mnémica, es decir, de la estabilidad y el mantenimiento de aquellos contenidos, adheridos a la memoria colectiva del grupo que los recuerda. De hecho, la propia representación de "memoria colectiva", tal y como opera en el campo de la sociología y la teoría cultural, requiere de dicha estabilidad. Dada la concepción tradicional de la memoria colectiva como el conjunto de "pilares" mnémicos a los que acude necesariamente el individuo (Halbwachs, 2004), es preciso el mantenimiento y la pervivencia diacrónica de los mismos, para dar sentido y sustancia a la entidad grupal.

No obstante que esta capacidad rememorativa colectiva pueda ser antropológica, está sensiblemente ligada a los mecanismos con los cuales las diferentes culturas producen y viven su temporalidad. De ahí la necesidad de investigar cómo se relaciona nuestro presente con esa exigencia de permanencia y estabilidad de las imágenes del pasado que evocamos.

En este sentido, la cuestión de la permanencia de la retención nmémica va a marcar uno de los rasgos específicos de nuestra propuesta. Defendemos, oponiéndonos a las tesis clásicas de Maurice Halbwachs según las cuales las memorias colectivas abarcan un espacio de solo tres generaciones $(2004, \mathrm{p} .80)$, que los recuerdos poseen una potencialidad para, a través de diferentes soportes culturales tan heterogéneos como los textos, monumentos o soportes electrónicos, sobrevivir a las personas que los percibieron. De ahí la necesidad de 
acudir a las teorías más actuales respecto a la memoria cultural y la técnica, para analizar la proyección que los recuerdos del pasado siglo, bajo los nuevos soportes, tienen en nuestro presente.

En segundo lugar, el cuestionamiento de si nuestra cultura "recuerda algo", dado el carácter simbólico y polémico que impregna a muchas de las memorias que pueblan nuestro panorama cultural, alude también a un ámbito estrictamente ético-político. Es decir, se trata de problematizar si contamos con recursos sociales y políticos para efectuar las consecuencias prácticas de dichos recuerdos, o, en otros términos, para ejercer las lecciones morales derivadas de aquellas memorias. Me refiero específicamente a movilizar los recuerdos de los eventos traumáticos a lo largo del siglo xx para, de forma preventiva, evitar su repetición en el futuro. Al fin y al cabo, tras un siglo plagado de conflictos bélicos, genocidios y, especialmente, de un evento que, como el Holocausto, tuvo tales proporciones $-\mathrm{y}$ fue objeto de un proceso retrospectivo de sublimación-, cabe preguntarse si esas memorias tienen la vivacidad y la presencia suficiente como para vertebrar nuestro campo político. El hecho de que se hayan cometido nuevos genocidios en lugares como Ruanda o Kosovo, que recuerdan a aquellos crímenes acaecidos en la primera mitad del siglo XX, induce a ser escépticos respecto a aquella posibilidad.

\section{Memoria y teoría de la historia}

A la hora de determinar las condiciones de las prácticas rememorativas, nuestro enfoque adopta la óptica que nos proporciona la reflexión filosófica en torno a los procesos de cambio histórico. La imposibilidad de entender nuestras prácticas mnémicas al margen de su relación con los restantes estratos temporales hace de la teoría de la historia —ya sea en la perspectiva koselleckiana (Koselleck, 1993) de la semántica de los tiempos históricos o en la teoría de François Hartog (2007) sobre los regímenes de historicidad - el marco teórico idóneo para ofrecer luz sobre estas cuestiones.

Introducimos algunas consideraciones para abordar estos temas desde esta disciplina filosófica. La clásica teoría agustiniana del tiempo como un triple presente definía el recuerdo como el modo mediante el cual el "pasado es en el presente" (San Agustín de Hipona, 2015, p. 307), 
careciendo de sustancia ontológica por sí mismo. Por lo tanto, la existencia del pasado requerirá de su mantenimiento o estabilidad, en aquella conciencia que, desde el presente, aseguraba su pervivencia.

Ahora bien, no podemos perder de vista en qué medida el propio presente también carece de ser. Requiere de su relación con el resto de instancias temporales para adquirir su propio estatuto. Como indicaba Paul Ricoeur (2004) al explicitar las aporías de la temporalidad, el presente nunca es, en la medida en que es la mera transición del pasado — que no es, porque ya ha sido — al futuro — que no es, porque todavía no ha ocurrido-. Consecuentemente, el instante presente adquiere su significación por su relación con los otros dos estratos temporales.

Partimos, por tanto, de un rechazo pleno a una temporalidad homogénea y lineal. Precisamente, la aplicación de esta tesis al ámbito colectivo, bajo el marco de una comprensión narrativa del tiempo histórico como la defendida en Tiempo y narración (Ricoeur, 2004), resulta en especial fructífera para dar cuenta del problema que centra nuestro estudio, de la focalización de nuestra cultura en el pretérito, del progresivo aumento de la presencia del pasado en nuestro presente.

Este fenómeno, a su vez, constituye un síntoma de la presencia de un eje de modificación en los mecanismos por los cuales los grupos humanos articulan su temporalidad o, lo que es lo mismo, de un índice de variación en las diferentes articulaciones producidas entre el "espacio de experiencia" y el "horizonte de expectativa" en cada presente histórico. En este sentido, ha sido ampliamente defendida la tesis (Boym, 2015; Gumbrecht, 2010; Hartog, 2007; 2012; Huyssen, 2007) según la cual esta obsesión por la memoria constituye una respuesta a la crisis del futuro, acaecida a finales del siglo Xx. Al fin y al cabo, estas nuevas tendencias culturales contrastan con la relación con el pretérito que caracterizó al —utilizando el término de Hartog— régimen de historicidad moderno.

2 "La experiencia es un pasado presente, cuyos acontecimientos han sido incorporados y pueden ser recordados [...] Algo similar se puede decir de la expectativa: está ligada a personas, siendo a la vez impersonal, también la expectativa se efectúa en el hoy, es futuro hecho presente, apunta al todavía-no" (Koselleck, 1993, p. 337). 
En su ensayo, "Transformations of the modern time regimen", Aleida Assmann (2013) destaca una serie de peculiaridades de este sistema temporal. Aquellas enfatizan su tendencia a dejar de lado el pasado; a purgar su presencia de nuestra vida social, política, cultural... Estos rasgos son la ruptura del tiempo, la ficción de un nuevo comienzo, la noción de una destrucción creativa, la invención de la historia y la aceleración del cambio. Todos estos conceptos reflejan una tendencia a dejar de lado el peso de la tradición, motivados por el carácter atrayente del futuro. De ahí que el fenómeno clave de la crisis de este sistema temporal se identifique con la desaparición del futuro de nuestro horizonte histórico. Este ha sido habitualmente localizado en 1989, año de la caída del muro de Berlín. Al fin y al cabo, este evento generó una conciencia pública en torno a la imposibilidad de un cambio cualitativo en el devenir histórico.

El esquema explicativo para dar cuenta de la relación causal entre la desaparición de los "futuros-presentes", del carácter del futuro como polo intencional al que tiende la sociedad humana, y la actual obsesión por la memoria, es el siguiente: el proceso de historización del pasado más inmediato, del ayer en sentido literal, responde a la tentativa de convertir el presente en pasado. Este es un proceso que, a su vez, solo puede estar motivado por el deseo de ver el presente como pasado o, lo que es lo mismo, de ver el presente tal y como lo veríamos desde la perspectiva del futuro. Por lo tanto, esta intención revela la nostalgia ante la posibilidad de poder situarnos en un futuro diferente, pretensión ya abandonada, desde el cual contemplar todo el horizonte temporal. Como indica Hans Ulrich Gumbrecht en Lento presente (2010, p. 32), ningún futuro puede convertir al presente en pasado, pues dada la citada crisis de futuro acaecida tras 1989, no es posible situarnos en un mañana cuantitativamente diferente al hoy, desde el cual representar nuestro presente como un pasado distante.

No obstante, nuestra interpretación de las condiciones, las motivaciones y la idiosincasia de esta "ola mnémica" va a orientarse por otro hilo argumentativo. Sin pretender negar la validez de la conexión entre la crisis del futuro y el retorno al pretérito, buscamos contribuir a profundizar y justificar el énfasis de Huyssen en otra tesis (2007, p. 18). Aquella destaca la posibilidad de entender esta 
tendencia a la conservación museística del pasado como una reacción ante la adopción, por parte de los procesos sociales de rememoración, de los esquemas de retención mnémica característicos de los nuevos soportes técnicos de memoria.

Por tanto, nuestro argumento se centra en la relación entre esta emergente cultura y los formatos electrónicos en los que se apoya. Por un lado, aquellos constituyen su condición material. Sin ellos sería imposible disponer de la enorme información acerca del pretérito que implementó estas prácticas culturales. Por otro, la extensión de sus cortos ritmos de obsolescencia y la falta de estabilidad de las imágenes y los contenidos que retienen han constituido la motivación de dicha ola mnémica como esfuerzo alternativo para asirse de modo permanente a un pasado que sirva de núcleo identitario colectivo. Se trataría, por lo tanto, de articular una práctica rememorativa que haga efectivo el propio recuerdo, asegurando la pervivencia o el mantenimiento de la huella mnémica en la retina de aquella memoria colectiva.

Para defender estas ideas, desarrollamos una serie de tesis. En primer lugar, expongo unas premisas en torno a qué vamos a entender por "recordar", siempre en la primera persona del plural, atendiendo al recuerdo colectivo. En segundo lugar, enunciamos una serie de ideas sobre la influencia que tienen los soportes mnémicos exteriores en los procesos sociales y culturales de rememoración que son objeto de nuestro estudio.

\section{La memoria más allá del individuo y del grupo}

El estudio, ya canónico, de Halbwachs (2004) en torno al fenómeno del "recuerdo" justificaba la imposibilidad de entender la actividad rememorativa individual independientemente de los marcos sociales a los que pertenece. De ahí la reivindicación de la categoría "memoria colectiva" como instrumento conceptual. Al fin y al cabo, defiende el sociólogo francés (Halbwachs, 2004, p. 40), el recuerdo de cada individuo requiere tanto un proceso de evocación como uno de reconstrucción. Esta última dependerá de pilares mnémicos externos, así como de coordenadas espaciotemporales conformadas colectivamente, es decir, de los denominados "marcos sociales de 
memoria”. Solo así se explicaría la dificultad a la hora de traer al presente recuerdos de la infancia. En aquella época, el influjo de la socialización era mucho menor. Dicho proceso traería consigo la adquisición de diversas reconstrucciones mnémicas tomadas del entorno social, que configura la actividad rememorativa individual.

De manera consecuente, la memoria colectiva tiene el carácter de entidad grupal que se sostiene por medio de las relaciones sociales, ante la cual cada memoria individual no sería más que un punto de vista parcial. No obstante, al dotar de una substancia colectiva a este tipo de memoria, Halbwachs no estaba únicamente fundamentando la alusión a entidades mnémicas grupales, sino que también desarrollaba una de sus limitaciones. El sociólogo francés defendió que la memoria colectiva solo operaba en las relaciones sociales, en las influencias puramente sincrónicas, que se mantenían entre un grupo humano, en un período temporal cerrado (Halbwachs, 2004, p. 80). De hecho, limitaba la pervivencia de la memoria colectiva a un espacio histórico trigeneracional — hijos, padres, abuelos-.

Ya que negaba la posibilidad de que hubiera depositarios mnémicos externos que, ejerciendo el mismo papel condicionante que atribuye a las dinámicas sociales, puedan sobrevivir a las generaciones que les dieron origen, el modelo de Halbwachs, por tanto, es estéril para entender cómo articulamos recuerdos de eventos que acaecieron hace más de ochenta años. Esta carencia es especialmente acuciante en nuestro presente, en el que están falleciendo los últimos testigos de los trágicos eventos del pasado siglo. Por ello, este modelo es insuficiente para responder al desafío que planteamos. De ahí la necesidad de corregir y complementar el bagaje analítico que propone Halbwachs, a partir de la tesis que, en los años ochenta, desarrollaron Jan y Aleida Assmann. Tanto el especialista en teoría de las religiones como la especialista en teoría cultural, para investigar en sus diferentes campos, debieron desarrollar un aparato conceptual alternativo con base en la siguiente tesis: el estudio de los condicionantes mnémicos grupales obliga a postular una memoria colectiva allende el espacio sincrónico en el que habita el grupo.

En una obra publicada hace escasos años, Cultural Memory and Early Imagination, Jan Assmann (2011) inició el proceso de recopilación y actualización de las tesis que, en décadas anteriores, habían 
defendido tanto él como Aleida Assmann. Al inicio de dicho texto plantea que sus revisiones sobre las relaciones de los colectivos con su pasado se estructuran en torno a tres ejes vertebrales: la memoria (que implica la referencia al pasado), la identidad (que refiere a la imaginación política) y la continuidad temporal (que alude a la formación de una tradición). Es este último punto, el de la pervivencia diacrónica de los mecanismos de relación con el pasado, el que nos sirve para tematizar su especificidad respecto a las tesis de Halbwachs. El sociólogo francés se preocupó por distinguir entre memoria colectiva y tradición. Esta última aludía a aquella "corriente viva" de la que heredamos nuestros rasgos culturales, mientras que Halbwachs se había limitado a aquello que se vivía o se comunicaba.

En este sentido, es preciso establecer una triple distinción respecto a cómo los recuerdos se constituyen como tales. En el primer nivel tendríamos la vivencia tal y como es percibida en el momento en que acaece. Posteriormente, el recuerdo de la misma, por parte de la conciencia individual, que estaría mediada por los condicionantes grupales vinculados a la noción de memoria colectiva. Finalmente, algunos de estos recuerdos, por su valor social, serán depositados en soportes simbólicos externos, que mantendrían la presencia de esa huella mnémica en la memoria del grupo y que codificarían el recuerdo posterior de las mismas. Tales soportes configurarían los marcos desde los que los eventos vividos serían representados por parte de las siguientes generaciones. Dichos depósitos materiales constituirían la condición de las prácticas rememorativas, más allá del contexto en el que surgen. De ahí la siguiente idea que plantea Jacques Derrida en Mal de archivo:

Ya que el archivo, si esta palabra o esta figura se estabilizan en alguna significación, no será jamás la memoria ni la anamnesis en su experiencia espontánea, viva e interior. Bien al contrario: el archivo tiene lugar en (el) lugar del desfallecimiento originario y estructural de dicha memoria (1997, p. 19).

La transición existente entre el segundo y el tercer nivel alude a la distinción de Jan y Aleida Assmann entre la memoria comunicativa y la memoria cultural. La noción de memoria comunicativa se superpone e identifica con la "memoria colectiva" de Halbwachs, es decir, remite a los condicionamientos que se llevan a cabo en 
el interior de un grupo humano, derivado de las relaciones comunicativas que mantienen en su día a día con el resto. La noción de memoria cultural, al contrario, trata de dar cuenta, no tanto de lo que se comunica de facto, sino de lo que se hereda y se reproduce de forma posterior a las tres generaciones que habitan ese espacio sincrónico. Así (J. Assmann, 2011, p. 7), la posibilidad de extender el ámbito de acción de la limitada memoria colectiva dependerá de la existencia de intermediarios, de depósitos de esa información, de fuentes de almacenamiento externo, convertidos en los transmisores de tal información. De ahí la relevancia, como destaca Jan Assmann (2011, p. 9), del paso histórico del ritual a la escritura. Es esta última la que fija la memoria en su soporte estable y la libera de los ritmos naturales del olvido y del recuerdo. Su aportación a nuestra tesis central radica, por tanto, en la constatación de que el acceso al pasado es textual, es decir, está mediado simbólicamente.

Por lo tanto, la presencia de una memoria cultural hace referencia a una dimensión exterior de la memoria humana que sobrevive a las generaciones en que se encarna. Esta ha sido definida mediante el término "posmemoria". La alusión a una memoria más allá de la memoria remite a los diferentes mecanismos simbólicos y culturales a través de los cuales se produce un reevocación, reprospectiva, siempre polémica y compleja, del pasado en el presente. El término se popularizó durante los años ochenta y noventa para dar cuenta de las diferentes características de la transmisión de la memoria traumática del Holocausto por medio de ciertos productos culturales que la acercaban al público general. De hecho, una de las pioneras en la defensa del concepto, Marianne Hirsch, argumentaba su valor heurístico, en "The generation of postmemory" (2008, p. 111), frente a las distinciones de Jan y Aleida Assmann, en la medida en que estas, defiende, no daban cuenta de las rupturas derivadas de los traumas colectivos en la transmisión cultural de la memoria. Se trata, por ende, de analizar cómo la memoria de este tipo de eventos transita de una generación a otra — de aquellos que vivieron esos fenómenos a sus sucesores-, mediante diversos formatos que traducen y modulan no solo esa información, sino también los vínculos afectivos con aquellos recuerdos. La categoría "posmemoria" tiene, así, un potencial íntimamente afectivo. 
Ahora bien, esta dimensión exterior de la memoria colectiva, denominémosla "posmemoria" o "memoria cultural", carece de límites temporales, por lo que da lugar a un bagaje de contenidos potencialmente infinito. Acumula consigo productos culturales del pasado, elaborados desde el presente, que pueden datar de siglos de antigüedad, ya que mientras sus soportes externos pervivan, también lo harán los propios contenidos mnémicos. De ahí la necesidad de establecer divisiones en función del rol que, en cada contexto, desempeñan estos contenidos, atendiendo a si poseen o no una función conectiva en dicho presente. Por este motivo, debemos recuperar la distinción que realiza Aleida Assmann en "Reframing memory" (2017) entre el canon y el archivo.

La noción de archivo abarca aquellos productos culturales que han dejado un tipo de traza en la historia de un grupo, pero que, al carecer de relevancia simbólica, son relegados a un formato material que meramente garantiza su conservación, no la puesta en práctica de su valor simbólico. Por este motivo, quedan localizados en un depósito al que acceden únicamente los especialistas en dicho campo. La noción de canon, al contrario, implica un acceso más democrático. El canon refiere a los elementos de una tradición cuya mera presentación está acompañada de una condición normativa; indica aquello que debe ser leído, citado, representado... o, lo que es lo mismo, que ejerce un rol en la función conectiva de la memoria cultural. Su rasgo específico consiste en que abarca los contenidos mnémicos en los que el contenido y la forma (Jan Assman, 2014, p. 82) están tan atados entre sí como pueden estarlo, de modo que este lazo trae consigo la dificultad a la hora de modificar el papel que dichos recuerdos desempeñan en la memoria colectiva presente, es decir, convierte la presencia de ciertos elementos de la cultura en más impermeables al paso del tiempo y al cambio político y social. En este sentido, los consigna como aquellos que no dejan de ser recordados.

La evolución y el mantenimiento de la memoria cultural, en el que algunos contenidos transitarán a lo largo de la frontera entre el canon y el archivo, dependerán de diversas prácticas culturales que predeterminarán el mantenimiento de los mismos. De entre aquellos, Jan Assmann distinguirá dos procesos: la repetición y la interpretación de rituales. Ambos no se caracterizan únicamen- 
te por producir significados y garantizar una continuidad temporal. Son, además, formas de presentificación, de hacer presente lo ausente, como mecanismos que permiten su reactualización en cada contexto. La relevancia de este proceso de "presentificación de lo ausente" es mucho mayor en nuestro contexto, en el que lidiamos con memorias que refieren a eventos de los que no quedan testigos. En este sentido, las características de este acto de rememoración, que posibilitan su fuerza conectiva, dependerán de los soportes mnémicos, de los intermediarios simbólicos que presentifican esa ausencia, por lo que estarán limitados y configurados por las peculiaridades de dichos formatos. Cuando los contenidos de la memoria colectiva no están formados por "memorias vividas", sino por "memorias imaginadas", la evocación de los mismos por parte de los miembros de un colectivo depende de los formatos - nunca neutrales o inocentes-que los vuelven a hacer presentes.

\section{Memoria y técnica}

Con base en esta dependencia con los soportes mnémicos que presentifican lo ausente, podemos adelantar la siguiente tesis: existe una dependencia estructural —en contenido y soportes- de la memoria humana respecto a los soportes externos de la memoria. Traigamos de nuevo a colación Mal de archivo de Derrida para reflejar esta condición:

[...] la estructura técnica del archivo archivante determina asimismo la estructura del contenido archivable en su surgir mismo y en su relación con el porvenir. La archivación produce, tanto como registra, el acontecimiento. Ésta es también nuestra experiencia política de las media llamados de información (1995, p. 24).

Dicha dependencia será profundizada y radicalizada cuando nos adentremos en las peculiaridades de los depósitos que median y producen recuerdos en nuestro presente. Al fin y al cabo, estos no se identifican ni con los rituales ni con la escritura como medios tradicionales de transmisión de información, sino con los medios electrónicos para el almacenamiento externo. El énfasis en estos últimos nos obliga a ir más allá de los planteamientos en teoría cultural desarrollados por autores como Jan y Aleida Assmann o Marianne Hirsch, 
para situarnos en el ámbito específico de la teoría sobre la técnica en tanto mecanismo de retención, transformación y producción de información. Como indica José van Dijck en Mediated Memories in the Digital Age:

Pese a que aprecio la claridad conceptual de Aleida Assmann, algo se pierde en su modelo de memoria cultural que me parece especialmente relevante a la hora de trasladar este concepto a un modelo de análisis utilizable. Pese a que ella hace énfasis en la interferencia de los marcos mentales y culturales en su teoría, claramente no tiene conocimiento respecto a cómo dar cuenta del papel de los medios y de las herramientas mediáticas en la formación de la memoria cultural (2007, p. 14). ${ }^{3}$

No obstante, la tesis que desarrollamos -mantener que existe un espacio de pervivencia simbólica (presentificación) de los recuerdos al margen del hecho de que sean recordados por los individuosno debe conducir a una identificación de la rememoración o de la experiencia de la memoria con el simple objeto técnico que nos permite acceder a aquella. Se trata, al contrario, de enfatizar, como un espacio de conocimiento autónomo y específico, en las formas de interacción entre dichos soportes técnicos y la mente humana cuando ejerce la actividad rememorativa.

En este sentido, llaman la atención las premisas del enfoque interdisciplinar con el que Van Dijck, en su ya citada Mediated Memories in the Digital Age (2007), aborda estas cuestiones. Propone un triple análisis, simultáneamente desde el ámbito de la psicología, la cultura y la tecnología. Se basa en la tesis según la cual la experiencia mnémica está encarnada (en la medida en que depende de la presencia fisiológica de un organismo que retenga la información), incrustada (en el interior de prácticas culturales intersubjetivas que condicionan la recolección de información) y habilitada (por dispositivos electrónicos). Es, por ello, dependiente del contexto sociotecnológico al que pertenece (Van Dijck, 2007, p. 78).

3 Tradución propia del texto original: "As much as I appreciate Aleida Assmann's conceptual clarity, something is missing from her model of cultural memory that appears to be highly relevant to further translation of this concept into a usable model of analysis. Although she stresses the interference of mental and cultural frameworks in her theory, she clearly does not know how to account for the role of media and media tools in the formation of cultural memory". 
Nos centraremos en el último ámbito, bajo la tesis de que existe una correlación entre la actividad mnémica y los media, que configuran y condicionan las interrelaciones entre pasado y presente. Para profundizar en cómo las memorias sobreviven a aquellas personas que las recuerdan, debemos, por tanto, adentrarnos en el ámbito de la teoría de la técnica.

Nuestro análisis acerca de cómo los medios técnicos de retención y transmisión de información afectan a nuestras prácticas rememorativas, comienza desmontando una premisa básica que subyace a la interpretación de los formatos de memoria, en buena parte de la tradición filosófica occidental. Nos referimos a la interpretación de la memoria y los media como realidades separadas, que pueden existir de forma autónoma, cuya relación es siempre contingente. Este modelo teórico tradicional se ha fundamentado habitualmente en el establecimiento de diversas clasificaciones binarias, cuyo carácter dicotómico es posible cuestionar. Recupera la memoria como algo puramente interno y privado, que siempre precede tanto al habla como a sus diversas modalidades de expresión o archivación. Al contrario, los media se presentan como instrumentos externos, artificiales, que ofrecen una información a disposición del público.

Desde que Platón criticara la utilización de la escritura como depósito de información (Platón, 2015, 227a-279d), las taxonomías filosóficas en torno al fenómeno del recuerdo concedían al ámbito de la memoria un espacio de intimidad y autonomía, imposibles de conciliar con nuestra justificación de nociones como "memoria colectiva" o "memoria cultural", así como con el panorama que dibuja la influencia de las nuevas tecnologías en nuestra actualidad.

Para intentar dar cuenta de la insuficiencia de dicho planteamiento, aludimos tanto a la obra clásica de Marshall McLuhan como a las tesis de algunos autores que, siguiendo un enfoque derridiano, han invertido algunos de los supuestos en torno a las relaciones entre memoria técnica y humana. Al fin y al cabo, como describe Belinda Barnet (2003), la inclinación a criticar la separación dicotómica entre pensamiento y tecnología ha formado parte de las tendencias teóricas de la deconstrucción, tanto en la obra de Derrida como en la de algunos de sus epígonos. 
Al inicio de su obra El modo de existencia de los objetos técnicos, Gilbert Simondon (2008) desarrolla una crítica a una de las formas más canónicas y radicalizadas del planteamiento dicotómico al que aludimos. Aquella es defendida por un humanismo simplista que contrapone el mundo de la técnica —enajenador y artificial— al de lo humano - el propio de la cultura-. Al ser ajenos entre sí, toda influencia o intromisión de la tecnología en este último no puede más que ser interpretada como una perversión o fuente de debilitamiento. Así define Simondon la idiosincrasia de este modelo:

La cultura se comporta con el objeto técnico como el hombre con el extranjero cuando se deja llevar por la xenofobia primitiva. El misoneísmo orientado contra las máquinas no es tanto odio a lo nuevo como negación de la realidad ajena. Ahora bien, este extranjero todavía es humano, y la cultura completa es lo que permite descubrir al extranjero como humano. Del mismo modo, la máquina es el extranjero; es el extranjero en el cual está encerrado lo humano, desconocido, materializado, vuelto servil, pero mientras sigue siendo, sin embargo, lo humano. La mayor causa de alienación en el mundo contemporáneo reside en este desconocimiento de la máquina, que no es una alienación causada por la máquina, sino por el no-conocimiento de su naturaleza y de su esencia (Simondon, 2008, p. 27).

Frente a aquel modelo, el filósofo francés defenderá que el mundo de lo humano y de la técnica mantienen una relación transductiva - atributo extensible a aquel vínculo existente entre memoria humana y memoria técnica-, en la que ninguna de ellas puede articularse o ser inteligible al margen de la otra (Simondon, 2008, p. 31). La transducción es exactamente el mismo concepto del que hace uso Bernard Stiegler en La técnica y el tiempo (1996). A lo largo de esta obra, Stiegler desarrolla pormenorizadamente las consecuencias de su interpretación antropogénica de la técnica.

Las implicaciones de esta tesis para el problema que abordamos son inmediatas. Tal y como defiende en el segundo volumen de $\mathrm{La}$ técnica y el tiempo (Stiegler, 1996, p. 193), las peculiaridades de las técnicas como soportes de las trazas del pretérito condicionan la manera en la que el hombre accede a su pasado, a los restos del mismo. La técnica, como medio retencional, se convierte, de acuerdo con la famosa expresión de McLuhan, en una extensión del hombre; en 
este caso, en su relación con los restos del pasado. La función configuradora de los formatos sobre la memoria y sobre sus contenidos tiene su traducción en la tesis según la cual "el medio es el mensaje [...] porque es el medio el que modela y controla la escala y forma de las asociaciones y trabajo humanos" (McLuhan, 1996, p. 30).

En este sentido, la transición de la escritura o los rituales (como formas de presentificación de lo ausente), a los soportes electrónicos, resulta prioritaria como objeto de nuestro análisis, especialmente en la medida en que, al revelar el contraste entre procesos de externalización y retención de información sobre el pasado, da cuenta de la especificidad de los modos de rememoración imperantes. De ahí la necesidad de atender a las tensiones diacrónicas entre memoria técnica y humana, así como a los mecanismos mediante los cuales aquellas configuran nuestra relación con el pasado en nuestro presente caracterizado por aquella "obsesión por la memoria”. Así, es posible aplicar las conclusiones extraídas en este ámbito al problema básico que nos atañe: la cuestión de si tras esta cultura de la memoria, apoyada sobre los actuales soportes técnicos de retención mnémica, habremos recordado algo.

La imposibilidad de entender la memoria humana y la memoria técnica de manera independiente no implica que ambas no carezcan de diferencias. Al contrario, son precisamente aquellas, combinadas con la tendente delegación por parte de la memoria humana de muchas de sus funciones de retención en su contraparte tecnológica, las que explican algunas de las tensiones que emergen entre ambas. Para profundizar cómo estas ideas de influencias derridiana aportan a nuestra tesis central, ofrezco una interpretación, en términos narrativos, de las distinciones que plantea Gilbert Simondon.

Es preciso matizar que estas reflexiones que vamos a extraer de un apartado concreto de El modo de existencia de los objetos técnicos (Simondon, 2008, pp. 137-150) no están vinculadas al objetivo que tiene en mente Simondon al plantearlas: dar cuenta de la complementariedad entre las funciones técnicas y humanas, derivadas del acoplamiento interindividual entre ambas (Simondon, 2008, pp. 31-40). Nuestro objetivo es meramente el de trazar aquellas diferencias, para determinar en qué medida la aplicación de los esquemas de retención 
técnicos a las prácticas rememorativas colectivas problematizan el alcance y la proyección de estas últimas.

En la obra de Simondon existen dos variables en torno a las que podemos dar cuenta de la retención mnémica técnica y humana. En primer lugar, la precisión y la exactitud de la información, y el amplio período de tiempo durante el cual es posible retenerla. En segundo lugar, la estructura o el orden en función de los que se presenta la información.

Respecto a la memoria técnica, Simondon defiende:

[...] la máquina es capaz de conservar durante un tiempo muy largo documentos monomórficos muy complejos, ricos en detalles, precisos. [...] Ahora bien, lo que caracteriza aquí la función de conservación de la máquina es que carece absolutamente de estructura; la película no registra de mejor manera figuras bien recortadas, por ejemplo imágenes geométricas, que la imagen desordenada de los granos de una taza de arena [...] el orden no existe para esta conservación de registros a través de la máquina, que no tiene la facultad de seleccionar formas (2008, p. 138).

Es decir, las máquinas pueden retener información de manera detallada, exacta y fiel a las experiencias que reproducen, durante un período de tiempo muy largo. Ahora bien, esta información se presenta sin ningún tipo de orden, por lo que no se agrupa en torno a estructuras perceptivas previas que les den sentido. Ninguna experiencia, ningún contenido o detalle, tiene mayor relevancia que el resto; no cumple un papel teleológico más significativo en las redes de recuerdos. La información es puramente aditiva o, lo que es lo mismo, carece de cualquier tipo de coherencia narrativa.

Por su parte, la memoria humana se define en términos opuestos. La retención de información tiene una fecha de caducidad mucho más cercana, ya que al acumular nuevos contenidos, los anteriores serán olvidados. Además, carece de gran precisión en sus detalles. Ahora bien, toda la información recibida se articula en función de unas formas y estructuras previas que le da sentido. Algunos de los propios eventos se convierten en ejes teleológicos que, por su relevancia — atribuida retrospectivamente-, configuran el significado del resto de contenidos. Es decir, la memoria humana tiene una función de síntesis o integración que la define como narrativa: derivada 
de formas precedentes de experiencia previa. "La memoria de la máquina triunfa en lo múltiple y en el desorden; la memoria humana triunfa en la unidad de las formas y en el orden" (Simondon, 2008, p. 140).

Estas diferencias son consecuencias de las modalidades de procesamiento de información. Es decir, en el caso del soporte electrónico, cuando un contenido es sustituido por otro, el precedente es totalmente borrado. El registro previo no forma ningún tipo de trasfondo (background) que funcione como criterio de selección o de organización de las experiencias posteriores, por lo que estas se presentarán con similar detalle, valor o significado. En el caso de la memoria humana, toda experiencia previa configura un principio organizado que da significado e integración a las vivencias posteriores, agrupadas en función de los criterios narrativos configurados por aquellas.

La memoria humana recibe contenidos que tienen un poder de forma en el sentido de que se recubren ellos mismos, se agrupan, como si la experiencia adquirida sirviera de código a nuevas adquisiciones, para interpretarlas y fijarlas: el contenido se convierte en codificación [...] la memoria es la función a través de la cual los a posteriori se convierten en a priori (Simondon, 2008, p. 141).

El eje de las diferencias básicas entre una memoria humana narrativa y una memoria técnica carente de estructura puede localizarse en el distinto foco al que se aplica la "plasticidad" en la retención de la información. Como indica Simondon: "La plasticidad en la memoria de las máquinas es la del soporte, mientras que la de la memoria humana es la plasticidad del contenido mismo" (2008, p. 140).

Son la noción de plasticidad y su influjo en la memoria colectiva los que deben protagonizar los siguientes párrafos. Para ello, tomamos como referencia, por su valor heurístico, la historia de las técnicas de exteriorización de información mnémica que realiza Bernard Stiegler en el segundo volumen de su obra La técnica y el tiempo (1996).

La actividad de construir instrumentos de retención mnémica, derivada de la imposibilidad de guardar en la memoria humana toda la información disponible, ha ido evolucionando históricamente en función de un aumento de movilidad en dos sentidos: del soporte en sí mismo y de los contenidos mnémicos respecto al soporte. Este 
doble movimiento de aceleración nos permite, siguiendo a Stiegler, establecer una clasificación histórica de estas técnicas en tres períodos, cada una de ellas inaugurada por tres eventos específicos.

La primera de ellas surge con la independencia de los procesos de transmisión de información respecto a la historia oral, fruto de la exteriorización de dichos contenidos en los soportes duraderos. Estos soportes se caracterizan por su solidez, resistencia a la erosión del tiempo y por su total ausencia de movilidad. Se circunscribe principalmente a los emblemas, lugares de culto... donde se inscribe una información de tal modo que es preciso que el receptor de la misma deba trasladarse al lugar donde aquella se encuentra.

El evento que da lugar a la segunda fase se identifica con el surgimiento de la escritura y la posibilidad de gravar objetos, que podrán ser enviados a través del espacio. Son designados por Stiegler como soportes móviles (1996, p. 194) y su ejemplo paradigmático serían las cartas. Ahora bien, pese al aumento de movilidad que implican, comparten con los soportes duraderos el vínculo férreo entre el mensaje y el soporte; en otros términos, entre la forma y el contenido. Recordemos que el mantenimiento de un lazo entre la forma y el contenido, tan fuerte como fuera posible, era el rasgo característico de los contenidos mnémicos asociados por Jan Assmann al canon, es decir, aquellos que tenían la capacidad de comprometer activamente a los individuos en su rememoración y en establecer los lazos conectivos de una memoria grupal.

Esta es la característica que es invertida con el paso a la tercera fase: la de los soportes dinámicos. Con este término, Stiegler da cuenta (1996, p. 195) del influjo de las nuevas tecnologías en los actuales soportes mnémicos de tipo electrónico. Estos posibilitan la independencia del contenido frente a su soporte material, en la medida en que los plazos temporales durante los cuales el mensaje es recibido, revisado, suprimido y actualizado tienden asintóticamente a cero. La aceleración en el intercambio de mensajes trae consigo la ausencia de permanencia en el tiempo de su contenido. Conforme más rápidos sean los ritmos de modificación de los contenidos mnémicos, menor será su estabilidad y permanencia en el tiempo. Así lo plantea Stiegler: 
Cuando la memoria se produce a una velocidad próxima a la de la luz, ya no es posible distinguir un acontecimiento de su toma, ni esta toma de su recepción o lectura: estos tres momentos coinciden en una sola realidad espacio-temporal debido a que toda demora y toda distancia entre ellos se encuentra eliminadas (1996, p. 178).

Sinteticemos en qué medida las teorías elaboradas en este apartado contribuyen a reflejar cómo se configuran nuestros recuerdos colectivos bajo los actuales formatos de "presentificación de lo ausente". Las implicaciones de la integración de este mecanismo de retención mnémica son evidentes. La elasticidad y la aceleración de estos soportes, así como el recurso más generalizado a los mismos en las últimas décadas, amenazan la propia noción de canon. Ningún contenido mnémico seguiría asociado a su formato original, rasgo característico del canon. Por lo tanto, ninguno de ellos sería impermeable al cambio y al paso del tiempo, condición que aseguraría su pervivencia y función práctica, su carácter de pilar mnémico en la memoria colectiva de un grupo humano. Esta condición pone en entredicho tanto la función práctica de estos recuerdos, como el alcance de la rememoración, en tanto actividad colectiva dependiente de estos mismos soportes. Hay una tendente reducción del tiempo de vida útil de los contenidos de la memoria colectiva. Al fin y al cabo, la volatilidad y la plasticidad de los soportes termina afectando y transmitiéndose a la memoria humana, que ha dependido siempre de aquellos.

\section{Memoria y tiempo sincrónico}

Podemos resumir estas tesis aseverando que el rasgo característico de nuestros soportes de memoria radica en la sincronicidad, es decir, en el carácter efímero y en la imposibilidad de mantenerse a lo largo del tiempo, esto es, en su carencia de una dimensión diacrónica. Los datos del pasado surgen y se agotan en el instante presente, dada la disolución de las distancias entre la lectura y la actualización o sustitución de los mismos. En el proceso a la hora de presentificar las imágenes del pasado por parte de estos mediadores en la actividad mnémica colectiva, prima la inmediatez. Así, no es de extrañar que la sincronicidad, como la hemos descrito, caracterice 
simultáneamente a nuestro actual régimen de historicidad, es decir, la descripción de nuestro actual tiempo histórico como un presente omnipresente. La conjunción de la rápida accesibilidad a experiencias de un período inmediato, con la ausencia de permanencia de su negativo en la retina de nuestra memoria colectiva, permite explicar que el panorama cultural y político de las últimas décadas haya sido caracterizado, además de por una obsesión por la memoria, por una tendencia a la amnesia colectiva. Como indica Huyssen: "La dificultad de la coyuntura actual es pensar en la memoria y la amnesia juntas en lugar de simplemente oponerlas" (2014, p. 22).

La alusión al olvido como patología de nuestro tiempo es una consecuencia de la intromisión de los ritmos de retención y consumo de información en nuestra actividad rememorativa. Al fin y al cabo, a la instantaneidad y la volatilidad de la información se suma su carencia de estructura. La tendencia al olvido deriva de la imposibilidad de volver impermeables algunos de aquellos contenidos respecto a la fugacidad instantánea que rige su transición del impacto de la imagen visual a su desaparición. No es de extrañar que el antropólogo francés Marc Augé haya defendido, en Las formas de olvido (2009), el recurso a este último, ante el exceso y la ausencia de estructura de las imágenes y las fuentes de información. La amenaza a nuestras prácticas mnémicas no deriva de la ausencia de información, sino de su ubicuidad y carencia de una estructura narrativa. La simultaneidad entre una obsesión por la memoria y una tendencia generalizada al olvido es el rasgo característico de nuestro particular tiempo histórico, el de un presente que, como defiende Manuel Castells (2005), es a la vez eterno — en tanto que integra en sí mismo a pasado y futuro- y efímero - en tanto que sus contenidos caducan constantemente-.

Ahora bien, esta paradójica relación entre recuerdo y olvido, que adquiere su mayor intensidad en nuestro régimen de historicidad, nos permite investigar la peculiar relación entre la sincronicidad de nuestros soportes de memoria - acompañados de la generación de un tiempo diacrónico en expansión-y la explosión de la memoria. Nuestra cultura mnémica se sostiene sobre la enorme disponibilidad de información, hecha posible por los soportes mnémicos. Pero, a su vez, surge como respuesta, y como resistencia, ante los ritmos de 
retención de información derivados de aquellos. Es decir, se articula como un esfuerzo por asegurar la pervivencia de ciertos pilares mnémicos, ante la amenaza de una amnesia generalizada, derivada de la tecnología de la información avanzada.

Nos encontramos, por lo tanto, con dos procesos históricos que no dejan de retroalimentarse y de oponerse. Cuanto mayor es la información que nos ofrecen nuestros media, más difícil resulta comprometerse con una imagen del pasado. Cuanto más volátil y frágil es el poso que dejan en nuestra memoria los actuales soportes, más intensa es la respuesta cultural de recuperación y mantenimiento de los emblemas del pasado. Cuanto más son absorbidos el horizonte de expectativa y el espacio de experiencia en un presente que no deja de achicarse, mayores son los esfuerzos por hacer del pretérito una fuente de estabilidad allende ese presente. Esta es una tentativa que no deja de problematizar los propios soportes técnicos de la memoria que posibilitan esta ola mnémica.

La actual cultura de la memoria se contextualiza, por tanto, en el interior de una tensión, en la que está en liza la propia posibilidad de construir una experiencia con sentido. Al fin y al cabo, la dinámica temporal que caracteriza el tiempo presentista se identifica con la temporalidad del trauma. El evento traumático es aquella vivencia que, por su intensidad, por sobrepasar el sistema de defensa de la conciencia, no es convertida en un evento pasado. Por ello, no dejará de volver a la conciencia, de forma inesperada y compulsiva, con la intensidad del propio presente.

La analogía entre la vivencia del trauma y la experiencia colectiva del presentismo, este traspaso de conceptos propios del psicoanálisis a asuntos relativos al tiempo histórico, ${ }^{4}$ se sustenta en las tesis desarrolladas por André Green en El tiempo fragmentado (2001). En este texto defiende la posibilidad de interpretar la obra de Sigmund Freud como apoyada en una teoría del tiempo, bajo la postulación de una temporalidad de la conciencia fragmentada que no se rige por la tripartición lineal pasado-presente-futuro. En aquella, todo es puro

4 Los problemas relativos a la proyección de la noción de trauma en el ámbito de la historia han sido más desarrollados en Pérez Baquero (2016). 
presente. En la neurosis traumática, plantea Green (2001, p. 17), "el tiempo se coagula". El presente se haya saturado de sí mismo.

Como defendía Freud en "Recordar, repetir y reelaborar" (2015), el paciente que ha sufrido un trauma repite esa experiencia en lugar de recordarla. Esta condición da lugar a una situación paradójica que Green define con un término cuyo contenido semántico tiene consonancia con las ideas que planteamos: una "memoria amnésica". A partir de la tesis según la cual la temporalidad depende de la experiencia de la conciencia (Green, 2001, p. 85), es decir, es relativa al sistema de percepción-conciencia, podemos identificar la vivencia traumática con la pura presentificación, ausente de cualquier distancia temporal que pudiera servir a la conciencia para tematizar y dar sentido a la misma. El marco temporal que inaugura este tipo de experiencias resulta análogo al del presentismo: todo futuro está ocluido en una experiencia pretérita que no ha pasado y que se agota en su mera instantaneidad y fugacidad. De ahí que, con base en esta analogía, podamos interpretar la actual obsesión mnémica, la ola patrimonial, como un mecanismo de superación del propio estado traumático presentista, incapaz de integrar aquellas experiencias; incapaz, en este sentido, de recordar y de comprometerse activamente con ellas.

La actual cultura de la memoria se asienta, consecuentemente, sobre una aporía fundamental, condición que la define como proyecto inacabado e interminable, que mantiene una relación de oposición mutua con aquellos soportes mnémicos que la hacen posible. Es una manifestación de la necesidad de habitar bajo horizontes temporales extendidos, frente a un espacio sincrónico en expansión. Por lo tanto, tal y como defiende Svetlana Boym en El futuro de la nostalgia, esta ola mnémica se constituye como un anhelo de la continuidad y la estabilidad propia de la memoria colectiva. "La aceleración del ritmo de la industrialización y de la modernización aumentó la intensidad de la añoranza de la lentitud del pasado, de la continuidad, de la cohesión social y de la tradición” (Boym, 2015, p. 42). Al fin y al cabo, aquello que termina amenazando el presentismo es la validez de la noción de memoria colectiva.

En su conocido ensayo sobre la obra de Maurice Halbwachs y 
la memoria colectiva, Ramón Ramos (1989, p. 80) ya apuntaba a esta tensión cuando refería a la aceleración de los ritmos y a la desestructuración del tiempo en Occidente. Al fin y al cabo, se trata de factores que revelan la fragilidad y la elasticidad de los marcos sociales de memoria en el interior de una temporalidad presentista. Estos rasgos resultan imposibles de compatibilizar con la estabilidad que les atribuye Halbwachs a los mismos. Como indica Huyssen en Memorias crepusculares:

La memoria [...] representa en cambio, el intento de desacelerar el procesamiento de información, de resistirse a la disolución del tiempo en la sincronicidad del archivo, de recuperar un modo de contemplación fuera del universo de simulación, información rápida y cadenas de cable, para reclamar algo de espacio de apoyo en un mundo de heterogeneidad, no sincronicidad y sobrecarga de información que confunde y con frecuencia amenaza (1995, p. 23).

La cultura de la memoria debe interpretarse, por tanto, como un anhelo por la continuidad y la estabilidad de la memoria colectiva, en el interior de una temporalidad sincrónica en expansión, que no deja de amenazar sus pilares $\mathbf{I}$

\section{Referencias}

Assmann, A. (2013). Transformations of the modern time regimen. En C. Lorenz y B. Bevernagr (Eds.), Breaking up Time. Negotiating the Borders between Present, Past and Future (pp. 39-56). Gotinga: Vandenhoeck \& Ruprecht.

Assmann, A. (2017). Reframing memory. Between individual and collective forms of constructing the past. En K. Tilsman, F. van Vree y J. Winter (Eds.), Performing the Past. Memory, History, and Identity in Modern Europe (pp. 37-51). Amsterdam: Amsterdam University Press.

Assmann, J. (2011). Cultural Memory and Early Imagination. Writing, Remembrance, and Political Imagination. Cambridge: Cambridge University Press.

Augé, M. (2009). Las formas del olvido. Barcelona: Gedisa.

Barnet, B. (2003). The erasure of technology in cultural critique. The Fibreculture Journal, (1). Recuperado de http://one.fibreculturejournal.org/fcj-005-the-erasure-of-technology-in-cultural-critique

Boym, S. (2015). El futuro de la nostalgia. Madrid: Antonio Machado Libros.

Castells, M. (2005). La era de la información. Vol. I. Madrid: Alianza. 
Derrida, J. (1997). Mal de archivo. Madrid: Trotta.

Freud, S. (2015). Inhibición, síntoma y angustia. En El yo y el ello y otros escritos de metapsicología (pp. 63-167). Madrid: Alianza.

Green, A. (2001). El tiempo fragmentado. Buenos Aires: Amorrortu.

Gumbrecht, H. U. (2010). Lento presente. Sintomatología del nuevo tiempo histórico. Madrid: Escolar y Mayo.

Halbwachs, M. (2004). La memoria colectiva. Zaragoza: Prensas Universitarias Zaragoza.

Hartog, F. (2007). Regímenes de historicidad. Presentismo y experiencia del tiempo. Ciudad de México: Universidad Iberoamericana.

Hartog, F. (2012). Sobre los regímenes de historicidad. En F. Dosse (Ed.), Historicidades. Buenos Aires: Waldhuter ediciones.

Hirsch, M. (2008). The generation of postmemory. Poetics Today, 29(1), 103-128. DoI: $10.1215 / 03335372-2007-019$

Huyssen, A. (1995). Memorias crepusculares. La marcación del tiempo en una cultura de amnesia. Buenos Aires: Prometeo Libros.

Huyssen, A. (2007). En busca del futuro perdido. Cultura y memoria en tiempos de globalización. Buenos Aires: Fondo de Cultura Económica.

Koselleck, R. (1993). Futuro-pasado. Para una semántica de los tiempos históricos. Barcelona: Paidós.

Mate, R. (2003). Memoria de Auschwitz. Actualidad moral y política. Madrid: Trotta.

McLuhan, M. (1996). Comprender los medios de comunicación. Las extensiones del ser humano. Buenos Aires: Paidós.

Pérez Baquero, R. (2016). Historia y trauma colectivo: límites, usos y abusos. Oximora, (8), 131-147. Recuperado de http://revistes.ub.edu/index.php/oximora/article/view/15266

Platón. (2015). Fedro. En Diálogos. Madrid: Gredos.

Ramos Torre, R. (1989). Maurice Halbwachs y la memoria colectiva. Revista de Occidente, (100), 63-81.

Ricoeur, P. (1999). La lectura del tiempo pasado. Memoria y olvido. Madrid: Ediciones Universidad Autónoma.

Ricoeur, P. (2004). Tiempo y narración. Vol. I Buenos Aires: Siglo XX.

San Agustín de Hipona. (2015). Confesiones. Madrid: Gredos.

Simondon, G. (2008). El modo de existencia de los objetos técnicos. Buenos Aires: Prometeo libros.

Stiegler, B. (1996). La técnica y el tiempo. Vol. 2. Gipuzkoa: Argialezche Ira. 
The Onion (1997, 4 de noviembre). U.S. Dept. of Retro Warns: "We may be running out of past”. Recuperado de https://politics.theonion.com/u-s-dept-of-retro-warns-we-maybe-running-out-of-pas-1819564513

Van Dijck, J. (2007). Mediated Memories in the Digital Age. California: Stanford University Press.

Winter, J. (2001). The generation of memory: Reflections on the "Memory Boom" in Contemporary Historical Studies. Canadian Military History, 10(3), 57-66. Recuperado de https://scholars.wlu.ca/cmh/vol10/iss3/5 